\title{
Does Trust Always Help Gender Role Attitudes? The Role of Individualism and Collectivism
}

\author{
Nabamita Dutta ${ }^{1} \cdot$ Lisa Giddings $^{1} \cdot$ Russell S. Sobel $^{2}$
}

Accepted: 28 June 2021 / Published online: 10 July 2021

(c) This is a U.S. government work and not under copyright protection in the U.S.; foreign copyright protection may apply 2021

\begin{abstract}
Social trust has a complex interrelationship with attitudes toward gender equality. Social trust has its origins in exchange relationships in preindustrial societies, lowering uncertainty in transactions and easing interpersonal exchanges. The degree to which this trust was extended to opportunities for women in commercial and societal roles, however, differed across cultures. Prior literature finds attitudes toward individualism and collectivism have significant implications for gender equality and patriarchal attitudes. We combine these ideas arguing that the degree to which social trust fosters gender equality depends upon the degrees of individualism and collectivism. Employing World Values Survey data across countries over time, we find that with low levels of individualism, and high degrees of collectivism, higher levels of trust are not effective in reducing the prevalence of gendered patriarchal attitudes - in fact it entrenches them further, worsening gender equality. However, as individualism rises, and collectivism falls, higher levels of trust become effective in reducing the prevalence of patriarchal beliefs. Thus, collectivistic beliefs stand as a barrier to future improvements in women's equality and economic rights in many societies; preventing social trust from being extended beyond traditional gendered roles.
\end{abstract}

Keywords Trust $\cdot$ Gender inequality $\cdot$ Gender role attitudes $\cdot$ Individualism $\cdot$ Collectivism

JEL Classification $\mathrm{J} 16 \cdot \mathrm{O} 11 \cdot \mathrm{Z} 10 \cdot \mathrm{I} 25$

Nabamita Dutta

ndutta@uwlax.edu

Lisa Giddings

lgiddings@uwlax.edu

Russell S. Sobel

russell.sobel@citadel.edu

1 Department of Economics, College of Business Administration, University of Wisconsin - La Crosse, La Crosse, USA

2 Baker School of Business, The Citadel, Charleston, USA 


\section{Introduction}

Trust among individuals is an indispensable component of economic development (Beugelsdijk et al., 2004; Whiteley, 2000; Zak \& Knack, 2001). Across disciplines, social scientists have reached a widespread consensus that social trust facilitates cooperation and collective action among individuals within a community (Durante, 2009). While the terms trust and social capital are often used interchangeably in the literature, there are important differences, as are discussed by Nooteboom (2007). Nooteboom (2007) concludes social capital entails reliance but does not necessarily include trust in the intentional sense. Prior literature has identified many different transmission mechanisms through which trust affects economic growth and development. These channels include effects on skill and educational attainment (Bjørnskov, 2009; Dearmon \& Grier, 2011; Özcan \& Bjørnskov, 2011; Papagapitos \& Riley, 2009), accountability and governance (Bjørnskov, 2012), total factor productivity (Bjørnskov \& Méon, 2015; Dearmon \& Grier, 2011), international trade (Greif, 1994; Guiso et al., 2009), and a variety of other aspects of human development (Özcan \& Bjornskov, 2011).

Prior research suggests modern social trust in societies, itself, has deep historical roots in exchange patterns from the preindustrial era (Dasgupta, 2005; Durante, 2009; Nooteboom, 2007). Trust served as a necessary pre-condition to the generalized development of a commercial society with trade, barter, and exchange. While modern developed economies usually rely upon formal contract law to enforce the terms of interpersonal exchanges between strangers, these legal mechanisms were not present in the preindustrial era, and remain underdeveloped even in some countries today. ${ }^{1}$ In such environments, exchanges are often confined to among those who have personal or familial relationships that form the foundations for trust (de Soto, 1989, 2000), which greatly restricts economic activity, exchange, and level of economic development. While trust, and social trust, may now be different from what happened in traditional societies, Durante (2009), Dasgupta (2005), and Nooteboom (2007) suggest important correlations that persist from these historical roots.

While the exchange of goods and services among individuals and social units (families, tribes, worker collectives, firms, etc.) helped build social trust over time, the degree to which this trust was extended to women in their social and economic endeavors has widely differed among societies. In many cultures the trust relationships remain to this day mostly limited to their historically patriarchal patterns. For example, many developing countries like India, Vietnam, Albania, and Thailand have relatively high levels of social trust using common measures, yet they suffer from heavily gendered attitudes favoring patriarchy.

In this paper, we argue that cultural traditions and values regarding individualism and collectivism affect the extent to which social trust is extended across genders to promote reductions in patriarchal attitudes and gender inequality. In highly collectivist (or low individualistic) societies the exchanges of goods, which were often done out of self-sacrifice for the good of the society and sometimes forcefully conduced or required by governmental-type structures, were handled mainly by the patriarchal heads of well-defined social units on the groups' behalf. Thus, the output produced by the female group members would be eventually exchanged or transacted by the male patriarchs in the group.

\footnotetext{
1 The term 'extended order' is often used when referring to this complex system of interpersonal exchange governed by formal and informal institutions (Hayek, 1988).
} 
While this fostered trust among the patriarchal heads, it often worked to solidify and entrench the gendered roles within the sub-groups-leading to high levels of social trust among the male members of society, that did not extend to women's roles in economic exchange or social groups and leadership. Thus, while trust was built, it did not work to tear down barriers to women's equality in society. In contrast, in societies that had high levels of individualism and low levels of collectivism, views of individual autonomy and rights empowered women to be equal members of these trust-building commercial and social exchanges and interactions. Thus, as women became important sources of goods and services upon which others relied for their survival and productivity, it helped to tear down gendered patriarchal attitudes. This has not been a global phenomenon. As reported by Stone (2018) in her blog for council on foreign relations, the World Bank reports that even today almost half of the world's economies have at least one legal constraint on women's rights to own property or conduct the same economic exchanges as their male counterparts.

Using individual-level panel data from waves of the World Values Survey (WVS) database, we explore how trust works in conjunction with social norms toward individualism and collectivism to affect attitudes about patriarchy and gender equality. Our results show that exchange-built trust on its own does not help reduce gendered attitudes, and in highly collectivist societies it even worsens the situation by entrenching patriarchal attitudes. In order to improve gender equality, our results show that trust needs to work with individualism. We find that as individualism rises and collectivism falls, higher levels of trust do indeed help to significantly reduce biased and gendered attitudes.

Let us state at the very outset that our estimates should be interpreted as association among the variables and not necessarily as causation. While we employ control variables, a battery of robustness checks, different measurement variables, and address sample selection bias using inverse probability weight estimates, the inherent complexity of these issues, which includes cognitive, emotional, relational features, and contextual variables, like sense of community, social justice, and human rights means any attempt to measure these types of attitudes and values (and their interrelationship) are often going to be inadequate to overcome all of the issues necessary for a controlled scientific experiment. This caveat is common in the literature on empirical inquiries regarding the variables we employ (Davis \& Williamson, 2019). ${ }^{2}$

Section 2 builds the theoretical arguments for our hypothesis based upon prior literature. Section 3 describes the data and Sect. 4 establishes our empirical methodology. In Sect. 5, we present our benchmark results. In Sect. 6 we conduct an extensive robustness analysis, and Sect. 7 concludes.

\section{Theoretical Foundation in Prior Literature}

Many factors influence cultural attitudes regarding gender equality. For example, economic development, the movement away from agriculture-based societies, and the associated decline in fertility rates have resulted in societies that are more likely to embrace equality between men and women. The relation between social hierarchies and historical patterns

\footnotetext{
${ }^{2}$ Murray (2006) points out that the finite-sample properties of IV estimates are problematic. If instruments are weak, IV estimators may not be an improvement over OLS estimators (Clemens et al., 2012). Persson and Tabellini (2006) note the difficulty in finding efficient, time varying instruments that are strictly exogenous.
} 
of oppression is often conceptualized in feminist theory using intersectionality following the work of Crenshaw (2017). It is an analytical framework framing how discrimination stems from patterns of social identification when multiple factors are present. In particular, in intersectionality theory the discrimination faced by a black woman, for example, is greater than (and not simply explained by) the combined discrimination against each factor (women/black) independently. Thus, the relationship can often be complex and intertwined with trust and discrimination along many dimensions.

Societies with less gender-biased attitudes tend to have measurable outcomes that reflect those attitudes toward equality including higher female labor force participation, higher rates of educational attainment for females, and greater participation in politics by women through voting rights and the holding of political offices and community leadership positions. It is also clear that 'institutions' - the formal and informal rules governing human interactions in a society-affect not only economic systems but also social attitudes as well (Tabellini, 2008, 2010). Institutions can reduce transactions costs, eliminate principalagent problems, improve collective action, and encourage economic growth.

Trust among individuals may be one of the most important dimensions of culture (Zak \& Knack, 2001; Tonkiss et al., 2000; Uslaner, 1999; Ostrom, 1998; Newton, 1997; Fukuyama, 1996; Coleman, 1990). Fukuyama (1996) claims that a nation's well-being and its ability to compete depends on the level of trust in society, while Arrow's (1972: 357) argument that a lack of trust explains the economic "backwardness" of some countries has implications about how trust in society can improve attitudes about gender equality. Arrow (1972) focuses on the importance of trust for reducing uncertainty in economic transactions thereby improving economic development. It follows that trust can potentially improve gender equality through the development of commercial exchange relationships between men and women as equals.

A variety of definitions of trust exist (Delhey \& Newton, 2005; Fukuyama, 1996; Luhmann, 2000; Misztal, 1996; Ostrom, 1998). At a societal level, Guiso et al. (2008) define trust as the propensity of a population to trust people that they do not know personally. Social trust is the belief that most other people can be trusted to behave in an honest way (Bergh \& Bjørnskov, 2011). Gambetta (2000) defines trust as a perception of the probability that other agents will behave in a way that is expected of them. The concept of trust is embedded in the nature of human interactions based upon expectations within exchange relationships, and the respect for the rights of others (including the non-expropriation of ownership rights to self and property).

Historically, trust is a necessary foundation to the development of a society with complex, commercial exchanges because trust reduces the risks in exchange and lowers transactions costs. While modern contract law and other formal institutions providing for the rule of law underpin most developed economies today to help overcome problems of trust in interpersonal exchanges between strangers (Hayek, 1988), this structure was not present historically and is still not present even today in all economies (de Soto, 1989, 2000). In the informal trading networks that exist within such environments, exchanges often remain confined to only between individuals who know each other personally, or who have long standing family relationships or religious associations that help build the foundations of trust (de Soto, 1989, 2000).

Trust is built among individuals through experiences in past and ongoing exchange relationships involving expectations and deliverables (Arrow, 1972; de Soto, 1989, 2000; Durante, 2009). Durante (2009) finds that social trust has its origins in exchange relationships in preindustrial societies. Employing high-resolution, growing-season, historical climate data, Durante (2009) finds that subsistence farmers faced substantial risk due to 
climatic variation and crop failures. Because of this, in geographically diverse societies, exchange among farming families and communities was necessary to cope with these negative climatic events for successful survival. Over time, trading and exchange relationships that were later reciprocated built trust. This trust then allowed and fostered even higher (riskier) levels of exchange and investment that became viable once higher levels of trust were in place in a self-reinforcing manner. This social trust lowered uncertainty in transactions and eased interpersonal exchanges that enhanced economic development and created widespread income-producing entrepreneurial opportunities for individuals within the larger society.

The degree to which this trust was extended to opportunities for women in commercial and societal roles, however, differed vastly among cultures. In many societies, even those with high levels of trust, these relationships remain embedded in their historically patriarchal patterns. The puzzle (that we hope to address) is why some societies that have built high levels of trust still retain these highly gendered patriarchal attitudes, while others do not, if these high levels of trust have common origins in exchange as the literature suggest.

Prior literature has found attitudes toward individualism and collectivism have significant implications for gender equality and patriarchal attitudes (Binder, 2019; Cho et al., 2015; Davis \& Williamson, 2019). We hypothesize that the degree to which the development of social trust through exchange fostered gender equality depends upon the degrees of individualism and collectivism in society. Let us now consider the literature on individualism and collectivism to enlighten our argument.

Hofstede's (1980) research in cross-cultural psychology identified the individualismcollectivism dichotomy for analyzing how these societal values relate to individual behavior. Hofstede developed an index of individualism that measures the extent to which it is believed that individuals are expected to take care of themselves as opposed to being strongly integrated and loyal to a cohesive group (Hofstede, 1980, 2001). In countries will high individualism, personal freedom and status are highly valued (Gorodnichenko $\&$ Roland, 2011). The importance of social values toward collectivism and individualism for various societal outcomes has now been well established (Cline \& Williamson, 2017; Davis \& Williamson, 2016; Gorodnichenko \& Roland, 2011, 2017).

Individualism and collectivism have complex interactions with social and health policies particularly observed in times such as the recent COVID-19 pandemic. Yadav et al. (2020) explain how 'syndemics' or 'synergistic epidemics' occur due to interactions between biological and socioecological factors. They can result in worse outcomes in areas with greater inequalities as the effects of a pandemic or other health event may worsen due to interactions within the diverse nexus of sociological and biological factors in a society. Yadav et al. (2020) explicitly examine how the pandemic has disproportionately affected individuals living with non-communicable diseases and reflect on strategies and policies to deal with these syndemics in countries with lower levels of income.

Movements for women's equality have been linked to individualistic cultures. Individualism is causally associated with the emergence of formal rules regarding individual political rights and civil liberties (Davis \& Abdurazokzoda, 2016; Licht et al., 2007). Davis and Williamson (2019) find that individualism is associated with greater gender equality. They show that the values emphasized by individualistic societies including autonomy, self-expression, creativity, and priority on individual rights generally promote egalitarianism. According to Gorodnichenko and Roland (2011), individualism emphasizes personal freedom and achievement, and as a result cultures that are more individualist award higher social status to personal accomplishments such as significant discoveries, innovations, or great artistic achievements regardless of the person's gender who accomplishes them. 
Davis and Williamson (2019) propose two ideas that underpin their hypothesis that individualism is associated with reduced patriarchal attitudes. The first is that underlying values of autonomy and individual rights transcend gender identities. Women are viewed as equals to men morally and in regard to fulfilling obligations that in collectivist societies are associated with gendered relationships (i.e., mother and wife obligations vs. father and husband obligations). In collectivist societies, women are subordinated to ascribed roles that de-emphasize their personal goals and prioritize their obligations to others in the group. Second, collectivist societies tend to be more hierarchical and patriarchal emphasizing the 'family' or 'tribe' as the structure serving the greater society. Collectivist societies require a degree of structure and accepted authority to which individuals must subscribe to accomplish the coordination of economic and social behavior. This structure generally is patriarchal in nature and acceptance of it is based on social and peer pressure, along with tradition. Female group members are subservient to the needs of the patriarchal heads to conduct actions on behalf of the group to fit into larger social goals.

In terms of relevance for our hypothesis, the commercial or exchange relationships in highly collectivistic societies were (and are) conducted among families or groups by the patriarchal authorities in those sub-groups, often as a self-sacrifice to accomplish group goals, rather than directly between autonomous individuals as a means to mutual advantageous improvement. This does help to build trust, but only among the patriarchal heads, and often works to solidify and entrench the gendered roles within the sub-groups. High levels of social trust are developed among the male members of society, but they do not extend to women's roles in economic exchange or social groups and leadership. Thus, as trust is built through exchange in collectivist societies it does not work to tear down barriers to women's equality.

On the other hand, in individualistic societies, views of individual autonomy and rights afforded women the opportunity to participate as equal members in these trust-building commercial and social exchanges and interactions. Female members of society became important sources of the goods and services that were exchanged. As social trust was built to higher levels in individualistic societies it resulted in improved attitudes toward gender equality and helped to reduce traditional patriarchal attitudes. In line with our hypothesis, Binder (2019) finds that in higher income countries, individualism is positively correlated with generalized trust and tolerance of outsiders and negatively correlated with belief in traditional gender roles.

One final important feature of the existing literature worth discussing is the multidimensional aspects of both individualism and collectivism. While one might think these are two sides of the same coin, so to speak, the literature has found that measuring each separately is necessary. Empirical studies generally include separate measures of both individualism and collectivism, although sometimes a single index is used. For example, Binder (2019) examines how separate measures of individualism and collectivism are correlated with the degree of redistribution and inequality. Steele and Lynch (2013) also employ separate measures of each in addressing the question of whether individualist or collectivist orientations best predict individual-level subjective well-being and whether the relationship between these larger beliefs and well-being has changed over time during China's transformation toward a market economy.

Triandis and Gelfland (1998) and Singelis et al. (1995), provide a variety of definitional differences between dimensions of individualism and collectivism separately. Definitionally, collectivism is seeing the self as a part of a collective of individuals accepting of the hierarchy and inequality within that collective that serves a group values, purpose, or goals. Collectivism is duty to others involving sacrifice, communal 
sharing, respecting the decisions of others with higher social standing, and a feeling of pride in the success of the group and others within the group. In authority ranking, people attend to their positions in a linear ordering. Individualism, on the other hand, is seeing the self as fully autonomous and believing that equality between individuals is the ideal. Individualism is depending on self, valuing personal identity, and a desire to be competitive and win.

According to Triandis (2001) people in collectivist cultures are likely to define themselves as a purpose-driven part of a group with each person serving different purposes toward an end, external goal. The determinants of social behavior are context driven and relationship are viewed as communal with in-group members. According to Markus and Kitayama (1991) people in different cultures have strikingly different conceptions of the self, of others, and of the interdependence and connectedness among individuals. They argue, for example, that in Asian cultures there is a high degree of individualism, with distinct conceptions of individuality, but also a high degree of collectivism in terms of attending to others, and harmonious 'fitting in' relationships. In Western societies, however, high individualism is decoupled from collectivism, in that there are no assumptions or values of overt connectedness among individuals. Instead people desire to maintain their independence from one another by caring for the self and expressing unique inner attributes. They suggest these different conceptions can influence and define the very nature of cognition and emotion both internally and toward other individuals and argue for their separate measurement.

With regard to commerce and exchange, Probst et al. (1999) rely on separate measures of individualism and collectivism to examine whether these values affect the manner in which people cooperate with one another. Those with high individualism behaved the most cooperatively in cases where maximizing personal outcomes also fostered intergroup goals, such as is present under market exchange in which production and trade for personal gain lead to greater degrees of societal, intergroup specialization and consumption. On the other hand, collectivists were least cooperative in these same settings, instead working best when dealing with problems in single ingroups. Clark et al. (1987) find that individuals with high communal orientation were more likely to allocate resources equally among each other out of a view of self-sacrifice and achieving a group goal. This subservient view of helping others, rather than fostering respect and trust often fostered a sense of distain. In contrast, individuals with low communal orientation fared better in fostering mutually advantageous hypothetical exchanges involving goods and services.

Thus, measures of both collectivism and individualism from this prior literature seem to have relevance for testing our hypothesis. To reiterate, in light of our discussion of the definitional differences, as higher levels of social trust are built through exchange interrelationships, the impact on views toward gender equality and traditional patriarchal attitudes will depend on the degrees of individualism and collectivism present in social structures and values. When these views are highly individualistic, and less collectivistic, these trust-building exchanges empower women and help to reduce gender inequality. In contrast, when either low individualism, or high collectivism are present, higher trust built through interactions and exchanges is limited to the males in the patriarchal structure, and often works to deepen the embedding of the authoritarian lines of traditional family gendered relationships, working to worsen gender inequality. We now turn to an empirical test of our hypothesis. 


\section{Data Description and Summary Statistics}

This section describes our key variables of interest in the empirical analysis including our measures of attitudes toward gender equality, trust, individualism, and collectivism. All variables come from World Value Survey (WVS) database. The World Values Survey, started in 1981, provides data from six waves of individual-level surveys using identical questions asked to respondents in nearly 100 countries regarding beliefs, values, and opinions about social, economic, and political issues. ${ }^{3}$ It also includes information about the demographic characteristics of the survey respondent (sex, age, education, etc.) and their self-reported economic characteristics (income, social class, etc.). We employ data from all six waves comprising the years 1981-1984, 1990-1994, 1995-1998, 1999-2004, and 2010-2014. Because each subsequent wave included more countries, the sample is unbalanced. Table 1 provides a listing of the descriptions and definitions for each of our variables that we will discuss as we introduce them, while Table 2 provides the summary descriptive statistics.

The data in Table 2 allow us to see the sociodemographic characteristics of the sample of data we analyze as well. Just over half of those in the sample (51 percent) are female respondents, and the average age in our sample is just under 41 years. About half of the individuals sampled were employed at the time of the survey, and about twenty percent live in large urban areas. Sixty percent are middle class, and just less than 2 percent are in the upper class. While the education variable is a coded index variable, the mean of 4.7 indicates the average person in the sample has some, but not a complete, secondary education (we will discuss these values later). We will discuss the descriptive statistics of our main variables as we present them below.

\subsection{Dependent Variables}

To measure gender inequality reflected in patriarchal attitudes, we start with three benchmark measures employed by Davis and Williamson (2019). The first is a dummy variable coded 1 for individual responses strongly agree and agree to the statement 'on the whole, men make better political leaders than women do'. In our analysis and tables, we refer to this variable as 'Men Better Political Leaders'. As can be seen in Table 2, the mean for our entire sample is about 50 percent for the 'Men Better Political Leaders' variable. The second measure is also a dummy variable assigned the value 1 for responses strongly agree and agree to the statement 'a university education is more important for a boy than a girl'. In our analysis and tables, we refer to this variable as "Univ. for Boys". The third measure is a dummy variable assigned the value of 1 for responses strongly agree and agree to the statement 'men make better business executives that women do'. In our analysis and tables, we refer to this variable as 'Men Better

\footnotetext{
3 The World Values Survey (WVS) data has been widely used by scholars and international development agencies for several decades. The survey data's validity, even specifically on the trust question we employ, has been demonstrated using experimental methods using other measures and independent data (Johnson and Mislin, 2012). For other work showing the validity and uses of this data to approach the same or similar issues see Hosseini and Lawrence (2018), Hamamuraet al., (2017), Li and Bond (2010), Tesch-Romer et al., (2008), Hudler and Richter (2002) However, some authors have expressed concerns and objections to the data, and its limitations in methodology and interpretation for complex social issues, and for a discussion of these concerns see Torpe and Lolle (2011).
} 
Table 1 Variable definitions and descriptions

\begin{tabular}{ll}
\hline Variables $\quad$ World Values Survey (WVS) Database Conditions/Definitions \\
\hline
\end{tabular}

Patriarchal attitudes

Men Better Political Leaders A dummy variable indicating if individuals agree or strongly agree to the statement 'men make better political leaders than women do'

Univ. for Boys

Men Better Bus. Execs

A dummy variable indicating if individuals agree or strongly agree to the statement 'a university education is more important for a boy than a girl'

A dummy variable indicating if individuals agree or strongly agree to the statement 'men make better business executives than women'

Men right to job

A dummy variable indicating if individuals agree or strongly agree to the statement 'men have more right to a job than women do'

PAI

PAI1

PAI2

Individualism

A constructed index of patriarchal attitudes based on \#1, \#2 and \#3 using principle components analysis

A constructed index of patriarchal attitudes based on \#1, \#2 and \#4 using principle components analysis

A constructed index of patriarchal attitudes based on \#1, \#2, \#3 and \#4 using principle components analysis

An index of individualism constructed based on principle components analysis of:

1. A variable ranging from 1 to 10 with 1 indicating govt. ownership should be increased and 10 indicating private ownership should be increased

2. A dummy variable indicating disagree or strongly disagree to the statement 'one of the main goals in life has been to make my parents proud'

3. A variable ranging from 1 to 10 with 1 suggesting homosexuality is never justifiable and 10 suggesting homosexuality is always justifiable

4. A variable ranging from 1 to 10 with 1 suggesting abortion is never justifiable and 10 suggesting abortion is always justifiable

Individualism1

An alternate index of individualism index constructed including \#1, \#2 and another variable control. Control ranges from 1 to 10 with 1 indicating none to the statement 'how much freedom of choice and control' and 10 stating a great deal

Individualism-Collectivism An alternate index including all components of individualism1 and collectivism components \#2, \#3 and \#4 (with collectivism measures inversely rescaled)

Collectivism

An index of collectivism constructed based on:

1. A dummy variable indicating if individuals respond quite proud or very proud to the question 'how proud of nationality'

2. A variable ranging from 1 to 10 with 1 indicating there should be larger income differences to incentivize individuals and 10 indicating incomes should be made more equal

3. A variable ranging from 1 to 10 with 1 indicating people should take more responsibility and 10 suggesting government should take more responsibility

4. A variable ranging from 1 to 10 with 1 indicating that competition is good and 10 suggesting competition is harmful

Educational Attainment

An ordered dummy ranging from 0 to 8.0 indicates no formal education and 8 a complete university education

Employed

Dummy variable assigned 1 if individual is full time employed, part time employed or self-employed, 0 otherwise

Age

Age of individual respondent

Town size

Dummy variable assigned 1 if town population is 500,000 or greater, 0 otherwise

Upper class

Dummy variable assigned 1 if self-reported class is upper, 0 otherwise 
Table 1 (continued)

\begin{tabular}{lc}
\hline Variables & World Values Survey (WVS) Database Conditions/Definitions \\
\hline Middle class & Dummy variable assigned 1 if self-reported class is upper middle or middle, \\
& 0 otherwise \\
Female & Dummy variable assigned 1 if individual is female, 0 otherwise \\
\hline
\end{tabular}

Table 2 Summary descriptive statistics of variables

\begin{tabular}{llllll}
\hline Variable & Obs & Mean & SD & Min & Max \\
\hline Men better political leaders & 283,196 & 0.5 & 0.5 & 0 & 1 \\
Univ. for Boys & 289,009 & 0.2 & 0.4 & 0 & 1 \\
Men Better Bus. Execs & 157,004 & 0.4 & 0.5 & 0 & 1 \\
PAI & 152,139 & 0.0 & 1.0 & -0.84 & 1.18 \\
PAI1 & 271,627 & 0.0 & 1.0 & -0.57 & 1.73 \\
PAI2 & 147,718 & 0.0 & 1.0 & -0.55 & 1.79 \\
Trust & 325,370 & 0.3 & 0.4 & 0 & 1 \\
Collectivism & 268,166 & 0.0 & 1.0 & -1.4 & 1.60 \\
Individualism & 247,852 & 0.0 & 1.0 & -0.84 & 2.29 \\
Individualism1 & 276,224 & 0.0 & 1.0 & -0.43 & 2.30 \\
Individualism-collectivism & 239,990 & 0.0 & 1.0 & -1.26 & 1.77 \\
Educational attainment & 296,811 & 4.7 & 2.2 & 0 & 8 \\
Female & 336,531 & 0.5 & 0.5 & 0 & 1 \\
Town size & 235,459 & 0.2 & 0.4 & 0 & 1 \\
Upper class & 284,337 & 0.0 & 0.1 & 0 & 1 \\
Middle class & 284,337 & 0.6 & 0.5 & 0 & 1 \\
Employed & 341,233 & 0.5 & 0.5 & 0 & 1 \\
Age & 337,058 & 40.7 & 16.1 & 13 & 99 \\
\hline
\end{tabular}

Bus. Execs.'. For the second and third measures, the sample means are 20 percent and 40 percent respectively. The final measure from Davis and Williamson (2019) termed 'PAI' (Patriarchal Attitude Index) is a constructed index based on the three measures above derived by principle component analysis, standardized in terms of mean and standard deviation.

As part of our robustness analysis, we consider alternative measures that include a related question, 'when jobs are scarce, men should have more right to a job than women'. This variable termed 'Men Right to Job' is a dummy variable assigned the value of 1 for responses of agree and strongly agree to this statement. We construct two additional indexes based on principle components analysis consisting of combinations of the measures, again standardized. 'PAI1' is based on 'Men Better Political Leaders', 'Univ. for Boys', and 'Men Right to Job', while 'PAI2' is based on all four variables 'Men Better Political Leaders', 'Univ. for Boys', 'Men Better Bus. Execs.', and 'Men Right to Job'.

Of worthwhile note, a higher score on all the PAI indices and individual variables is associated with higher levels of gendered or gender-biased attitudes that are patriarchal, prioritizing men over women. Because these are dependent variables, then, any independent variable with a negative coefficient helps to reduce these patriarchal views, or 
alternatively promote attitudes of gender equality, while those with positive coefficients tend to increase patriarchal views and thus worsen gender equality. We will also drop our use of quotes around these terminology-based variables for ease of exposition.

\subsection{Independent Variables}

Trust is one of our main independent variables of interest. Following an extensive set of studies (Bjørnskov, 2012; Johnson \& Mislin, 2012; Mikucka et al., 2017; Tabellini, 2008, 2010; Uslaner, 2003), we construct our measure of trust based on the question 'generally speaking, would you say that most people can be trusted or that you can't be too careful in dealing with people?' We construct a dummy variable taking the value 1 if individuals respond most people can be trusted; and 0 otherwise. Approximately 30 percent of individuals in this sample responded affirmatively that most people can be trusted.

Our other independent variables of interest are measures of individualism and collectivism. We rely on Hofstede's commonly used measure of individualism (Cline \& Williamson, 2017; Davis \& Williamson, 2016; Gorodnichenko \& Roland, 2017) applied to the WVS individual level data, following Davis and Williamson (2019) and Beugelsdijk, Maseland, and van Hoorn (2015). ${ }^{4}$ This procedure utilizes the following four questions from the WVS to construct the index: (1) 'private ownership of business and industry should be increased versus government ownership of business and industry should be increased', (2) 'one of my main goals in life has been to make my parents proud', (3) 'abortion is never justifiable', and (4) 'homosexuality is never justifiable'. Principle component analysis is used to create the 'Individualism' index variable based on these four questions. The index is standardized, and higher values denote greater individualism.

The inclusion of the questions related to abortion and homosexuality, while in line with the prior literature, could perhaps be broadening the measure to include variables that are not really linked with individualism but rather may simply confirm stereotypes or are codetermined with attitudes toward gender. We thus consider another constructed measure of individualism we term 'Individualism1' that omits these two variables and in their place includes an alternative variable 'Control' in the principle components analysis with the first two questions based on responses ranging from 1 to 10 to the question 'how much freedom of choice and control do you have in your life?' with higher numbers indicating more control (higher individualism).

As we discussed earlier, the prior literature often uses a second, separate measure of collectivism simultaneously in the empirical analysis. Based on Steele and Lynch (2013) we construct our 'Collectivism' variable based on a principle components analysis of four other variables from the WVS. The first underlying variable is a dummy variable based on the question of national pride, 'how proud of nationality' coded 1 for answers very proud and quite proud. The second underlying variable is based on the question providing a range of responses from 'income should be made more equal' (coded 10), versus 'we need larger income differences as incentives' (coded 1). The third also varies from 1 to 10 and is based

\footnotetext{
${ }^{4}$ Hofstede's original measure provides information on cultural values at a national rather than individual level (Hofstede, 2001; Hofstede 1980), Davis and Williamson (2019) and Beugelsdijk et al. (2015) employ the responses to the four individual-level WVS survey questions that capture the traits identified in Hofstede's measure of autonomy, the right to a private life, weak family ties, less conformity, and capitalism and market imperfection. The WVS individualism measure is highly correlated with Hofstede's original measure (0.77).
} 
on the question 'people should take more responsibility to provide for themselves' versus 'the government should take more responsibility to ensure that everyone is provided for'. Higher numbers denote that government should take more responsibility. The final variable in the collectivism index variable is based on attitudes towards competition with 1 indicating 'competition is good' and 10 indicating that 'competition is harmful'. For all four underlying variables and the overall index itself, higher values indicate higher levels of collectivist attitudes. As can be found in Table 2, the mean for the national pride variable is 0.9 , for the income differences/incentive variable is around 5 , for the responsibility variable is approximately 6 , and for the competition variable about 3.2. The index of collectivism arrived at through principle component analysis of these four variables is standardized in terms of mean and standard deviation.

In our robustness section we also present results in which a single variable reflects the combined attitudes toward both individualism and collectivism, rather than including the variables separately. Our single combined index variable we call 'Individualism-Collectivism' is derived based on a principle components analysis using all of the underlying variables in both of the other measures simultaneously. For consistency in the combined index we invert the collectivism measures, so they move in the opposite direction. In that single index, then, higher values represent higher individualism and lower collectivism simultaneously while lower values represent the opposite.

\subsection{Control Variables}

We include an array of control variables based on the prior empirical literature on attitudes toward women's rights, gender equality, and patriarchal beliefs. The first is a measure of educational attainment. Higher education has been shown to be significantly associated with improved views toward gender equality in a multitude of prior studies (Bjørnskov, 2009; Del Boca \& Locatelli, 2006; Heineck, 2004; Seguino, 2011). As educational attainment rises, individuals realize the worth of all individuals (Bjørnskov, 2009), and while some frame the argument in terms of education specifically (Dearmon \& Grier, 2011; Dinda, 2008), others approach the issue through impacts on adult social networks (Putnam, 2000), dropout rates (Coleman, 1988), or graduation rates (Knack \& Keefer, 1997; LaPorta et al., 1997). Whatever the channel, we expect that higher educational attainment helps to mitigate gendered attitudes in society (and thus should have a negative estimated coefficient in our specifications because our dependent variables increase in gendered patriarchal beliefs and decrease with beliefs consistent with gender equality). Our variable 'Educational Attainment', based on Seguino (2011), is constructed using a variable coded from 0 to 8 , where 0 indicates no formal education, 1 indicates an incomplete primary education, 2 indicates a completed primary education, 2 indicates an incomplete secondary education (vocational/technical), 4 indicates a completed secondary education (vocational/technical), 5 indicates an incomplete secondary (university/college preparatory) education, 6 indicates a completed secondary (university/college preparatory) education, 7 indicates an incomplete university education, and 8 represents a completed university education.

Our next independent variable controls for the differing attitudes toward gender equality between urban and rural areas (Zhang et al., 2007), creating a dummy variable 'Town Size' indicating the survey respondent lives in a town with a population greater than 500,000 . Urbanized areas have higher density, fostering contact among individuals, and more diverse workplaces less reliant on manual labor, with higher workplace coordination and interaction among genders. For the same reasons we control for whether the individual 
is currently employed. Social class, as stratified by income levels, has also been found to be correlated with attitudes towards gender equality and gendered roles (BaliamouneLutz, 2007; Del Boca \& Locatelli, 2006; Donno \& Russett, 2004; Forsythe \& Korzeniewicz, 2000; Heineck, 2004; Seguino, 2007b, 2011), so we control for self-reported income classes of individual respondents. We include dummy variables for upper class and middle class, with lower class as the omitted group. ${ }^{5}$

Our next control variable is the individual respondent's age. Seguino (2011) finds significant generational shifts in gender attitudes with younger individuals more likely to have more gender-equal attitudes. Studies have also shown that children are increasingly less likely to adopt traditional patriarchal attitudes as more women are joining the workforce (Fernandez et al., 2004; Seguino, 2007a). Thus, we expect 'Age' to have a positive estimated coefficient indicating that older individuals hold more gender biased, and patriarchal attitudes. Lastly, we follow Davis and Williamson (2019) in controlling for the gender of the survey respondent as women should be less likely to hold patriarchal attitudes.

\section{Empirical Methodology}

Based on our hypothesis, we want to explore how trust's impact on gender attitudes is affected by individualism and collectivism. For our main hypothesis, we model gendered (patriarchal) attitudes (GenAtt ict $_{\text {) }}$ of individual $i$ living in country $c$ at time (wave) $t$ as a function of interpersonal trust (Trust ${ }_{\mathrm{ict}}$ ), individualism (Individualism ${ }_{\mathrm{ict}}$ ) and/or collectivism $\left(\right.$ Collectivism $\left.\mathrm{ict}_{\mathrm{ict}}\right)$ and the set of individual level covariates $\left(\right.$ Controls $\left._{\text {ict }}\right)$ discussed above. Our benchmark equation includes both Individualism and Collectivism interacted with Trust. We do, however, check the robustness of our results later with each measure included alone in the specification as well as with the single combined variable capturing both on a single dimension, as well as with our alternative measures of individualism based on a different sample of questions. However, to begin the benchmark empirical specification is as follows

$$
\begin{aligned}
\text { GenAtt }_{i c t}= & \beta_{0}+\beta_{1} \text { Trust }_{i c t}+\beta_{2} \text { Individualism }_{\text {ict }}+\beta_{3}\left(\text { Trust }^{*} \text { Individualism }_{i c t}\right. \\
& +\beta_{4} \text { Collectivism }_{i c t}+\beta_{5}\left(\text { Trust } * \text { Collectivism }_{i c t}+\gamma_{i} \text { Controls }_{i c t}\right. \\
& +\mu_{i}+\theta_{t}+\varepsilon_{i c t}
\end{aligned}
$$

where $\mu_{i}$ is the country fixed effect, $\theta_{t}$ is the time (wave) specific effect, and $\varepsilon_{i t}$ is the random error term. Country fixed effects account for time invariant country effects (like being landlocked or being on the coast, colonial origin, climate, and religious or ethnic differences). Likewise, time fixed effects to control for global time trends or economic events. The two interaction terms Trust $*$ Individualism and Trust $*$ Collectivism are of most interest in our analysis and testing of our hypothesis. The coefficients of interest are $\beta_{1}, \beta_{3}$ and $\beta_{5}$. While $\beta_{1}$ captures the direct impact of the Trust on patriarchal attitudes, $\beta_{3}$ and $\beta_{5}$ capture the indirect effects through individualism and collectivism at specific values for those variables. In this context, we are interested in estimating the marginal impact of Trust on patriarchal attitudes. Through partial differentiation of Eq. (1), this is given by $\frac{\delta \text { GenAtt }_{i c t}}{\text { STrust }_{\text {ict }}}=\beta_{1}+\beta_{3}$ Individualism $_{\text {ict }}+\beta_{5}$ Collectivism $_{i c t} . \frac{\delta \text { GenAt }_{i c t}}{\delta \text { Trust }_{i c t}}<0$ implies that patriarchal

\footnotetext{
5 The middle-class dummy variable is coded 1 for responses of individuals belonging to upper middle class and middle class.
} 
Table 3 Trust, individualism/collectivism and patriarchal attitudes_-benchmark specifications

\begin{tabular}{|c|c|c|c|c|}
\hline & $\begin{array}{l}(1) \\
\text { Men Better } \\
\text { Political Leaders }\end{array}$ & $\begin{array}{l}\text { (2) } \\
\text { Univ. for Boys }\end{array}$ & $\begin{array}{l}\text { (3) } \\
\text { Men Better Bus. Execs }\end{array}$ & $\begin{array}{l}(4) \\
\text { PAI }\end{array}$ \\
\hline Trust & $\begin{array}{l}0.0001 \\
(0.004)\end{array}$ & $\begin{array}{l}0.018 * * * \\
(0.005)\end{array}$ & $\begin{array}{l}0.006 \\
(0.007)\end{array}$ & $\begin{array}{l}0.0149 \\
(0.0148)\end{array}$ \\
\hline Collectivism & $\begin{array}{l}0.001 \\
(0.002)\end{array}$ & $\begin{array}{l}-0.0003 \\
(0.003)\end{array}$ & $\begin{array}{l}-0.001 \\
(0.004)\end{array}$ & $\begin{array}{l}-0.00288 \\
(0.00817)\end{array}$ \\
\hline Trust*Collectivism & $\begin{array}{l}0.0002 \\
(0.004)\end{array}$ & $\begin{array}{l}0.006 \\
(0.004)\end{array}$ & $\begin{array}{l}0.006 \\
(0.005)\end{array}$ & $\begin{array}{l}0.0145 \\
(0.0117)\end{array}$ \\
\hline Individualism & $\begin{array}{l}-0.007 \\
(0.004)\end{array}$ & $\begin{array}{l}0.002 \\
(0.007)\end{array}$ & $\begin{array}{l}-0.004 \\
(0.005)\end{array}$ & $\begin{array}{l}-0.00961 \\
(0.0121)\end{array}$ \\
\hline Trust*Individualism & $\begin{array}{l}-0.014 * * * \\
(0.004)\end{array}$ & $\begin{array}{l}-0.013^{* * * *} \\
(0.003)\end{array}$ & $\begin{array}{l}-0.013^{* *} \\
(0.004)\end{array}$ & $\begin{array}{l}-0.0264 * * \\
(0.0100)\end{array}$ \\
\hline Educational Attainment & $\begin{array}{l}-0.016^{* * * *} \\
(0.001)\end{array}$ & $\begin{array}{l}-0.018^{* * * *} \\
(0.001)\end{array}$ & $\begin{array}{l}-0.018^{* * * *} \\
(0.001)\end{array}$ & $\begin{array}{l}-0.0383 * * * \\
(0.00333)\end{array}$ \\
\hline Female & $\begin{array}{l}-0.128 * * * \\
(0.006)\end{array}$ & $\begin{array}{l}-0.079 * * * \\
(0.006)\end{array}$ & $\begin{array}{l}-0.145^{* * *} \\
(0.009)\end{array}$ & $\begin{array}{l}-0.295^{* * *} \\
(0.0186)\end{array}$ \\
\hline Town size $(>500 \mathrm{k})$ & $\begin{array}{l}-0.011 \\
(0.008)\end{array}$ & $\begin{array}{l}-0.013 \\
(0.010)\end{array}$ & $\begin{array}{l}-0.011 \\
(0.011)\end{array}$ & $\begin{array}{l}-0.0216 \\
(0.023)\end{array}$ \\
\hline Upper class & $\begin{array}{l}0.038^{* *} \\
(0.015)\end{array}$ & $\begin{array}{l}0.056^{* * * *} \\
(0.014)\end{array}$ & $\begin{array}{l}0.020 \\
(0.014)\end{array}$ & $\begin{array}{l}0.039 \\
(0.029)\end{array}$ \\
\hline Middle class & $\begin{array}{l}0.005 \\
(0.005)\end{array}$ & $\begin{array}{l}0.0004 \\
(0.004)\end{array}$ & $\begin{array}{l}-0.002 \\
(0.005)\end{array}$ & $\begin{array}{l}-0.004 \\
(0.010)\end{array}$ \\
\hline Employed & $\begin{array}{l}-0.014 * * * \\
(0.003)\end{array}$ & $\begin{array}{l}-0.0196 * * * \\
(0.004)\end{array}$ & $\begin{array}{l}-0.017 * * * \\
(0.004)\end{array}$ & $\begin{array}{l}-0.033^{* * * *} \\
(0.009)\end{array}$ \\
\hline Age & $\begin{array}{l}0.001 * * * \\
(0.0002)\end{array}$ & $\begin{array}{l}0.001 * * * \\
(0.0002)\end{array}$ & $\begin{array}{l}0.0004 * * \\
(0.0002)\end{array}$ & $\begin{array}{l}0.001 * * \\
(0.0004)\end{array}$ \\
\hline Constant & $\begin{array}{l}0.588 * * * \\
(0.026)\end{array}$ & $\begin{array}{l}0.327 * * * \\
(0.040)\end{array}$ & $\begin{array}{l}0.859 * * * \\
(0.012)\end{array}$ & $\begin{array}{l}0.903 * * * \\
(0.025)\end{array}$ \\
\hline Observations & 136,699 & 138,593 & 89,510 & 87,775 \\
\hline Pseudo R sq./ R-squared & 0.14 & 0.10 & 0.17 & 0.20 \\
\hline
\end{tabular}

Probit and OLS Specifications: Probit specification estimates with robust standard errors clustered by country are in columns (1), (2), and (3). Column (4) are estimates from an OLS specification with robust standard errors clustered by country. The dependent variables are dummy variables in columns (1) to (3) and constructed index of patriarchal attitudes in column (4). We control for wave (time) fixed effects and country fixed effects. See Table 1 for variable definitions. Standard errors in parenthesis. Statistical significance indicated as: $* * * 1 \% ; * * 5 \% ; * 10 \%$

attitudes decline as trust increases. $\frac{\delta G^{-e n A t t_{i c t}}}{\delta \text { Trust }_{\text {tct }}}>0$ would mean the opposite - that patriarchal attitudes increase with trust. Whether $\frac{\delta G_{\text {ien }} \text { Att }}{\delta \text { Trut }_{i c t}}$ will be $>,=$, or $<0$ depends on the sign and magnitude of $\beta_{1}, \beta_{3}, \beta_{5}$ as well as the sign and magnitude of the underlying values of the Individualism and Collectivism variables. Based on our hypothesis, we expect $\beta_{3}$ to be negative, reflecting the desirable effects of higher individualism for trust's impact on equality, while $\beta_{5}$ is expected to be positive reflecting the harmful effects of exchange-derived trust 
under collectivist societies. For the individual dependent variables that are binary in nature, we employ probit estimation methods.

\section{Benchmark Results}

In Table 3, we present our first set of benchmark results. Probit specifications with robust standard errors clustered by country are considered in columns (1), (2) and (3) for the binary dependent variables. For the principle-components-derived index dependent variable in column (4), an ordinary least squares (OLS) specification is considered including country and time fixed effects along with robust standard errors clustered by country. To be clear, our preferred specification uses the overall PAI index measure as it is the one most closely related to the prior literature and this variable is based on the most meaningful principle components of all three other measures.

Strikingly, our results for the control variables and main variables of interest are similar regardless of which measure we use, whether it be one of the three individual values or the index based on principle components analysis. Starting with our control variables, educational attainment is negative and significant as expected indicating that individuals with higher levels of education are less likely to hold gendered, patriarchal attitudes. Also as expected, females are less likely to hold patriarchal attitudes. The prevalence of patriarchal attitudes also rises with age and falls with employment status as expected. The other controls produce insignificant or mixed results across specifications.

Turning to our main variables of interest to our hypothesis, the interaction terms between trust and both collectivism and individualism have the expected signs, showing that the impact of trust on gender biases falls with individualism ( $\beta_{3}$ is negative) and rises with collectivism ( $\beta_{5}$ is positive). In specifications involving interaction terms, the individual significance of the coefficients is not the appropriate consideration. Rather it is the joint significance of the terms that matters, and this joint significance can be tested not only for the omission of both variables, but it also can be tested for differing underlying values of the conditioning variable. The magnitude and statistical significance usually vary for differing values of the interacted variables (Brambor et al., 2006). It is possible, for example, that the combination of effects is statistically significant or insignificant at different values of individualism or collectivism, regardless of the individual significance of either coefficient in the regression. Thus, we need to examine the conditional effect for a range of values of individualism and collectivism (Berry et al., 2012; Brambor et al., 2006; Braumoeller, 2004). In addition, because our specifications in the first three columns involve probit specifications the coefficients presented in Table 3 are not the true underlying marginal effects, which must be separately calculated and can be of different significance levels than the probit coefficients. To aid in interpretation we thus present the calculated marginal effects for the endpoints and average values in Table 4, along with the levels of statistical significance.

In Table 4 we explore how the sign and magnitude of $\frac{\delta \text { GenAt }_{i c t}}{\text { STrus }_{i c t}}=\beta_{1}+\beta_{3}$ Individualism $_{\text {ict }}+\beta_{5}$ Collectivism $_{\text {ict }}$ varies for different values of individualism and collectivism, moving from individuals with strong collectivistic attitudes and low individualistic attitudes to ones having strong individualistic attitudes and low collectivistic attitudes. To achieve this, we evaluate $\frac{\delta G e n A t t_{i c t}}{\delta \text { Trust }_{i c t}}$ at three sets of values - [maximum (high) individualism, minimum (low) collectivism], [mean individualism, mean collectivism] and [minimum (low) individualism, maximum (high) collectivism]. We report the 


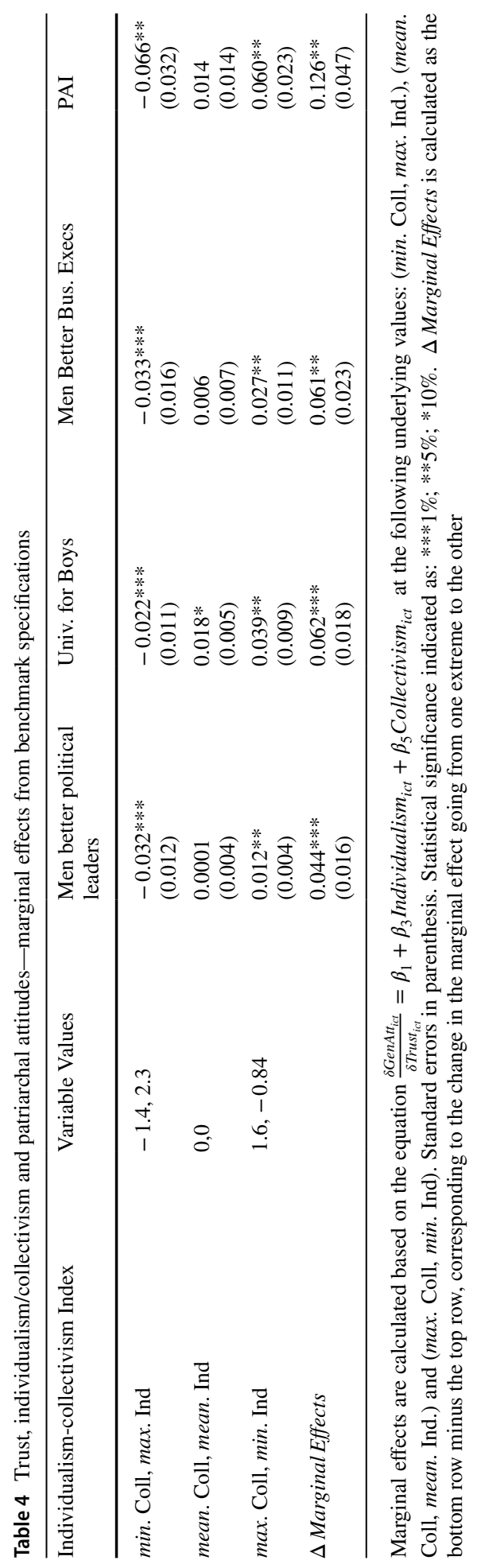


marginal effects for all the dependent variables reported in the previous table of benchmark results.

For all independent variables, we find that for high (max.) individualism and low (min.) collectivism, the estimated marginal effect, $\frac{\delta \text { GenAt }_{i c t}}{\delta \text { Trust }_{i c t}}$ is negative and statistically significant. What this means is that under conditions of low collectivism and high individualism, as trust is improved through social exchange an interaction, this is associated with lower prevalence of patriarchal beliefs (or, alternatively stated, stronger beliefs toward gender equality). As we move toward the average values, reflecting a movement away from individualistic values and toward collectivistic values, these partial derivatives move toward (and become insignificantly different from) zero.

Continuing, as one moves down the rows of the table to conditions of high collectivism and low individualism, the estimated marginal effect, $\frac{\delta G e n A t t_{i c t}}{\delta \text { Trust }_{i c t}}$ becomes positive and significant. What this means is that under conditions of high collectivism and low individualism, as trust is improved through social exchange an interaction, this is associated with higher (stronger) prevalence of patriarchal beliefs (or, alternatively stated, weaker beliefs toward gender equality).

The final row of the table $\Delta$ Marginal Effects shows our key estimate of importance, the absolute change in the marginal effect of trust when moving from [max. individualism, min. collectivism] to [min. individualism, max. collectivism]. Because of the slightly confusing directional nature of the signs of these variables, and the fact that the estimates from Table 3 are difficult to interpret probit coefficients (not marginal effects), this calculated change in marginal effects is much clearer and can be directly interpreted as a percentage point changes in probabilities. Thus, the change in marginal effects summary measure provides perhaps the best and clearest interpretation of our results. What the value of 0.04 in the first column shows is that high individualism and low collectivism are associated with a 4.4 percentage-point reduction in the probability that a given survey respondent will hold the patriarchal value indicated (and thus have a one for the value of the dependent variable) as trust is built in society, relative to the case of low individualism and high collectivism. ${ }^{6}$ In this case it is holding a belief that men make better political leaders than women. Alternatively stated, for every 100 survey respondents this would lead to a reduction of 4 in the expected number of individuals answering affirmatively to this patriarchal question. Because the mean value across the sample for this variable is 0.5 , it means currently on average about half, or 50 percent, of the survey respondents agree or strongly agree with this statement. For a country at that average level, this change would approximately reduce the value from 50 to 46 percent of respondents answering affirmatively. This 4 percentage-point change, when considered relative to that mean of 50 percent is a meaningful 8 percent reduction ( 4 divided by 50 ) in the proportion answering they hold this patriarchal value. The final row of Table 4 also shows that this 4 percent differential is statistically significant at the 1 percent level.

\footnotetext{
${ }^{6}$ More precisely, it is the difference in the change in the probability of an affirmative response when going from low trust to high trust ( 0 to 1 ) between high individualism/low collectivism cases and low individualism/high collectivism cases. Because evaluating these both at low trust (0) results in multiplication by zero for all trust variables, and taking the difference cancels out all other variables that are held constant, it more clearly can be viewed as the differential in the probability at the high value of trust (1) as we state in the text. This number could also be interpreted as the additional relative reduction in patriarchal values when the beliefs are more individualistic/less collectivistic relative to the opposite case when going from a case of low trust to high trust.
} 
Similarly, high individualism and low collectivism are associated with a 6.2 percentage-point relative reduction in the percentage of individuals holding the view that a university education is more important for boys than girls as trust improves (relative to the alternative). The sample mean for this variable is 20 percent, so when this change is evaluated as a percentage of the mean value, it implies a 30 percent (6 divided by 20) reduction in the number of individuals agreeing with the patriarchal belief that a university education is more important for boys than girls under conditions of high trust. For the statement that men are better business executives the change in the marginal effect is 6.1 percentage points, and given the mean value of this variable is 40 , the change is a 15 percent relative reduction in the percent answering affirmative to this statement relative to the mean under conditions of high trust. These are sizeable and meaningful changes in public opinions toward the equality of women and are statistically significant as is shown in the table.

The first three dependent variables all are binary, so the change occurs over the 0 to 1 interval (100 percentage points). The PAI variable has a wider range of underlying values from a minimum of -0.84 to a maximum of 1.18 , which is a range of 2.02 , and the variable is not inherently a percentage. Because it is based on the answers to all three questions using principle components analysis, the minimum value can be thought of as approximately corresponding to answers coded as zero for all three questions (most gender equal) and the maximum value corresponds to answers coded as one for all three questions (most patriarchal). Thus, a change within the two-point range of this variable converts roughly to half as big of a change within the one-point range of the underlying binary variables.

More succinctly, then, the equivalent percentage-point change would be found by dividing the $\Delta$ Marginal Effects number by two for the PAI index variable. Thus, the value of 0.126 shown in the table converts to the equivalent of a 6.3 percentage-point reduction in the percentage of survey respondents agreeing with the (principle component) of these patriarchal statements. This number is directly comparable to the values shown in the table of 4,5 , and 6 percentage points for the other binary variables, and is of approximately the same magnitude. To find the percentage change relative to the mean is slightly more complex because the three underlying variables that compose the index have different mean values, but their overall combined mean is roughly 0.37 , implying roughly a 17 percent reduction in overall patriarchal attitudes, again in line with the other estimates (which were 8,15 , and 25 percent on the individual variables). Because this index is based on those three underlying variables it makes sense that the values from the index fall in the middle of the range produced by the individual variables. For all of our forthcoming robustness tables, we present this $\Delta$ Marginal Effects calculation as the final row in the main estimation table for ease of interpretation. We will not provide the additional calculations of the percentages relative to the means in the body of the text in all cases, but an interested reader can find them by dividing the tabled values by the same mean values given above.

\section{Robustness Analysis}

In this section we conduct an array of robustness checks to ensure our results are consistent across alternate measures of our main variables of interest, to different specifications involving subsets of the individualism/collectivism measures, and methods of estimation. 


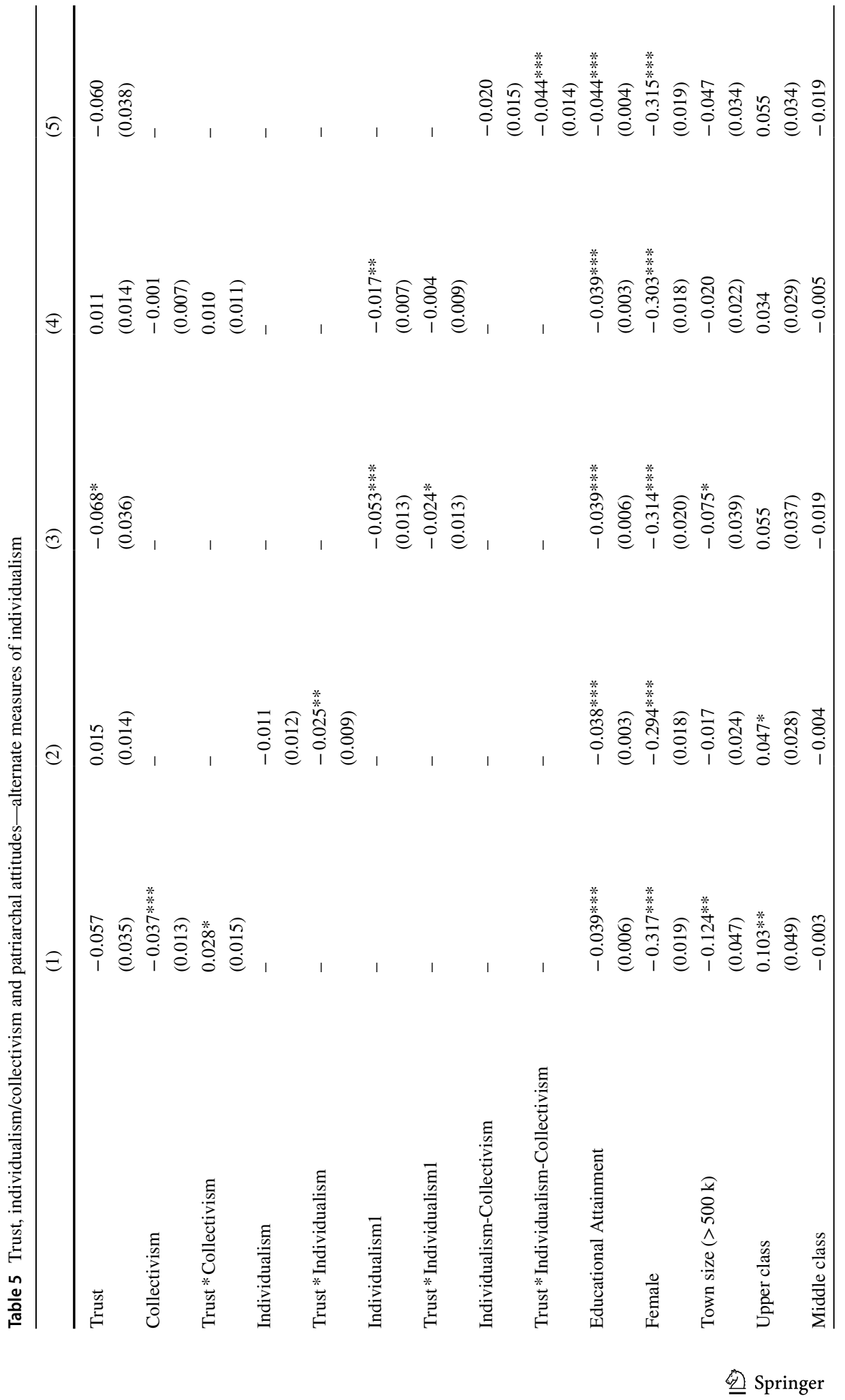




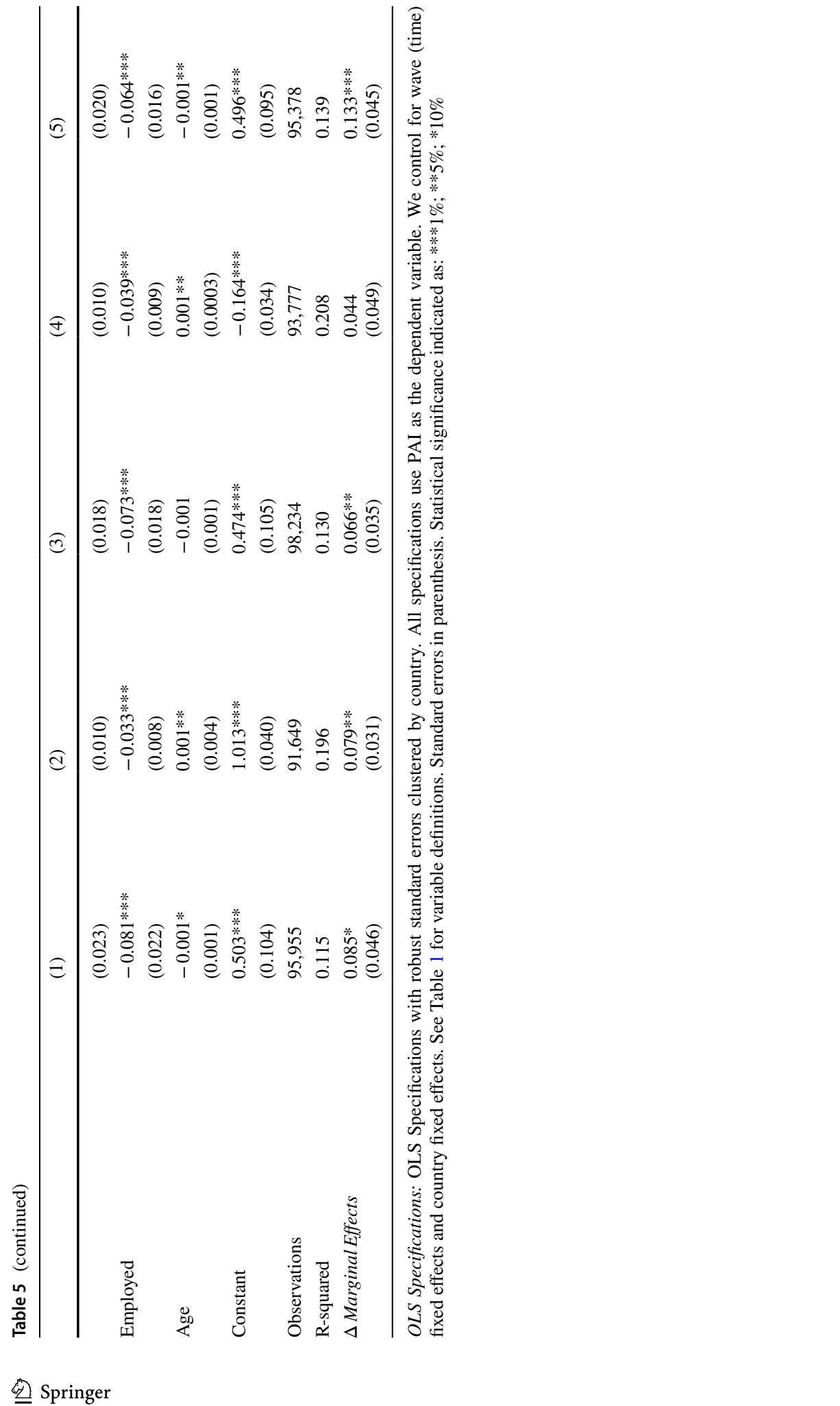




\subsection{Trust Interacted with Either Individualism or Collectivism Individually}

While the prior literature has stressed the multidimensional nature of individualism and collectivism and generally includes measures of both simultaneously in an empirical specification, the possibility that they are co-determined and multicollinear cannot be ruled out. Thus, as a starting point we consider specifications that include only one or the other using our preferred dependent variable which is the PAI index derived from the principle components analysis of the three underlying variables. Table 5, columns (1) and (2) show the results when one of the pair variables is excluded and the other retained. For example, column (1) shows the results when only the collectivism measure and its interaction is included without the individualism measure, and column (2) shows the opposite. The results remain robust, the signs and significance of the interactions retained, and the associated $\Delta$ Marginal Effects values are similar, the changes of 0.085 and 0.079 over the two point range of the PAI variable, which would correspond to reductions of 4.25 and 3.95 percentage points respectively in the average percentage agreeing with the principle component of the patriarchal statements.

\subsection{Alternate Measures of Individualism}

For our next pair of robustness results in Table 5 we show the estimates using the alternate measure of individualism, Individualism1, that drops the questions used in the Beugelsdijk et al. (2015) as well as Davis and Williamson (2019) measure of individualism regarding abortion and homosexuality and replaces them with the Control variable measuring self-control and determination discussed earlier. We show the results using this variable both by itself in column (3) and simultaneously with collectivism also included in column (4) to match the specification shown in the final column of Table 3. The estimated $\Delta$ Marginal Effects values are almost identical to the prior values using the Beugelsdijk et al. (2015) measure of individualism in the specifications omitting collectivism (now 0.066 instead of 0.079), however they are smaller than with the Beugelsdijk et al. (2015) measure for the one also including collectivism (now 0.044 instead of 0.126 ). ${ }^{7}$ This is likely because our revised Individualism 1 measure includes the new 'Control' variable that is correlated more strongly with the Collectivism variable. For this reason, and just to consider robustness, the final column in Table 5 shows the results when a single variable is constructed using the principle component all of the underlying variables from both the measures of collectivism and the revised Individualism1. This necessitates inverting the scale for the collectivism measures so that the single index had high values for high individualism and low collectivism, and vice versa. Somewhat interestingly, this single combined measure produced the second highest $\Delta$ Marginal Effects value of 0.133 .

Taking all five robustness checks in Table 5 as a whole, the median effect across them (0.079) remains squarely in line with our prior conclusion, an additional (and significant) relative reduction of about 4 percentage points in the percentage of individuals holding patriarchal attitudes as trust improves with high individualism, low collectivism relative to cases of low individualism, high collectivism.

\footnotetext{
7 Again, the numbers in the table for the change in marginal effects can be converted to approximate percentage point reductions by dividing by 2 (the range of PAI) and multiplying by 100 (to convert out of decimal form), and subsequently to a percent reduction relative to the mean by dividing that resulting number by 37 .
} 


\subsection{Alternate Patriarchal Attitudes Index}

Next we check the robustness of our results to the alternate PAI indices discussed earlier. Recall our main PAI index, taken from Davis and Williamson (2019) is based on a principle components analysis of the responses to the three questions 'Men Better Political Leaders', 'Univ. for Boys', and 'Men Better Bus. Execs.'. For our robustness analysis, we consider alternative measures that include 'Men Right to Job' based on the related question, 'when jobs are scarce, men should have more right to a job than women'. Our first alternative index 'PAI1' is based on the responses to the questions 'Men Better Political Leaders', 'Univ. for Boys', and 'Men Right to Job', while our second alternative index 'PAI2' is based on all four questions 'Men Better Political Leaders', 'Univ. for Boys', 'Men Better Bus. Execs.', and 'Men Right to Job'. Given the sample sizes within the underlying question data, these different definitions result in significantly different usable samples. As can be seen in Table 2, the 'Men Better Bus. Execs.' variable has about half as many usable observations when compared to the other two measures included in PAI. Thus, including it in the index results in a significant reduction in sample size. Our alternatively created PAI1 definition that replaces this variable thus significantly increases the sample size. The PAI2 variable that includes all four variables returns to a smaller sample but shows how this additional dimension would affect our benchmark results on the smaller sample. Again, for all, higher values for the dependent variable reflect more gendered attitudes, while lower values reflect more gender equal attitudes.

Columns (1), (2) and (3) of Table 6 present the results with PAI1 and columns (4), (5) and (6) present results for PAI2. In columns (1) and (4), we re-run our benchmark specification in column (4) in Table 3 but consider PAI1 and PAI2 as the dependent variables instead. In columns (2) and (5), we repeat the exercise but employ Individualism1 as the measure of individualism. Finally, in columns (3) and (6), we consider the single combined Individualism-Collectivism variable. We find similar significant effects and the expected signs for all specifications. The calculated $\Delta$ Marginal Effects produce results in line with our prior estimations as well, with all the findings significant as is shown in the final rows of the table. The median value here of 0.104 is similar to our prior estimates, and perhaps even a bit stronger, with a relative reduction of about 5 percentage points in the percentage of individuals holding patriarchal attitudes as trust improves with high individualism, low collectivism relative to cases of low individualism, high collectivism. Thus, our conclusions remain unchanged. ${ }^{8}$

\subsection{Inverse Probability Weight (IPW) Estimates}

Cultural traits such as trust can be simultaneously determined with individualism and collectivism. With higher individualism, people may increase trust in each other as well. Such simultaneous determination can lead to endogeneity and, thus, our estimates can be biased.

\footnotetext{
8 We have also checked the robustness of our results to the inclusion of additional controls related to marriage, having children, attitudes toward women as single parents, religious affiliations, and general adherence to religion. These results are available upon request.
} 


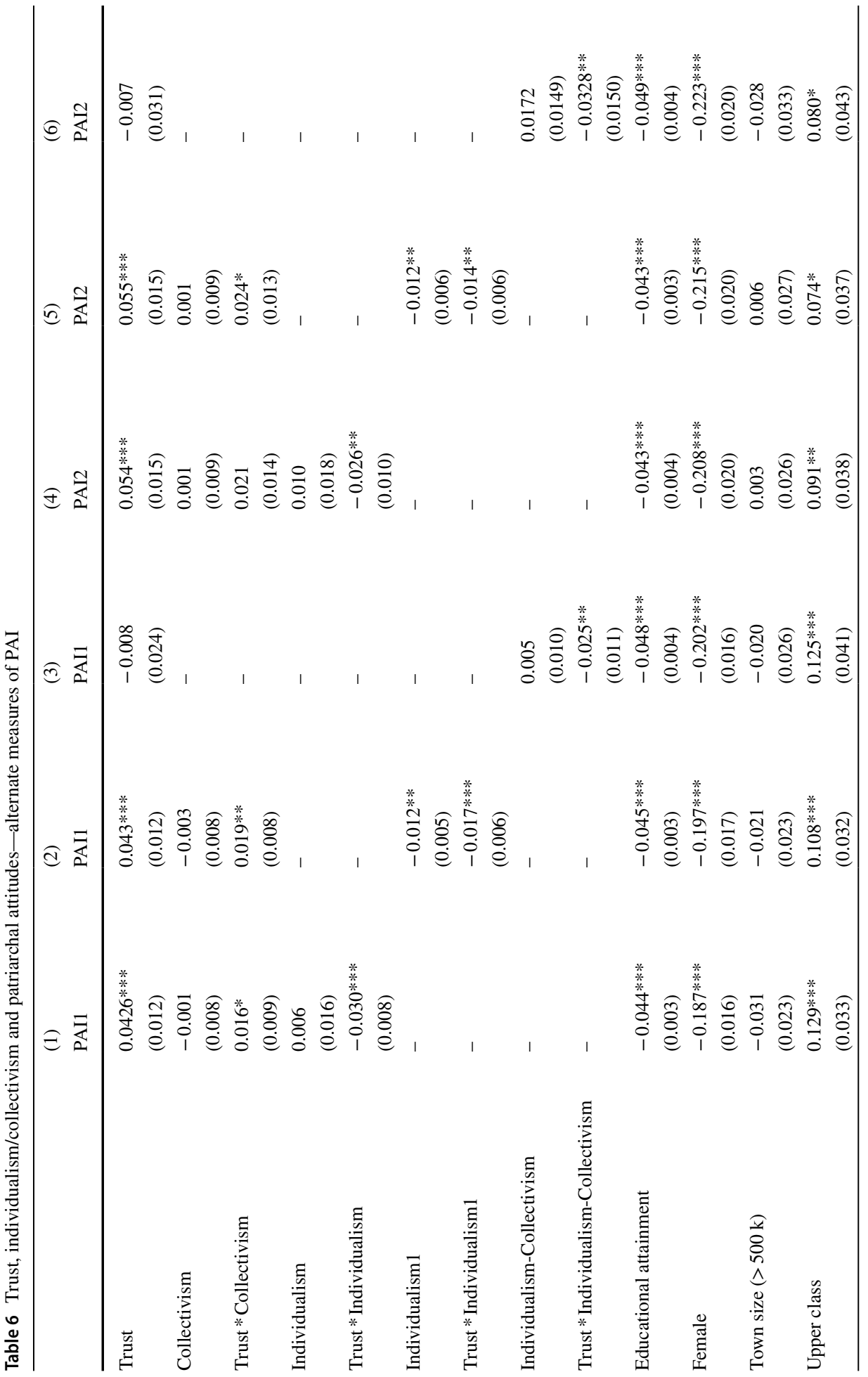




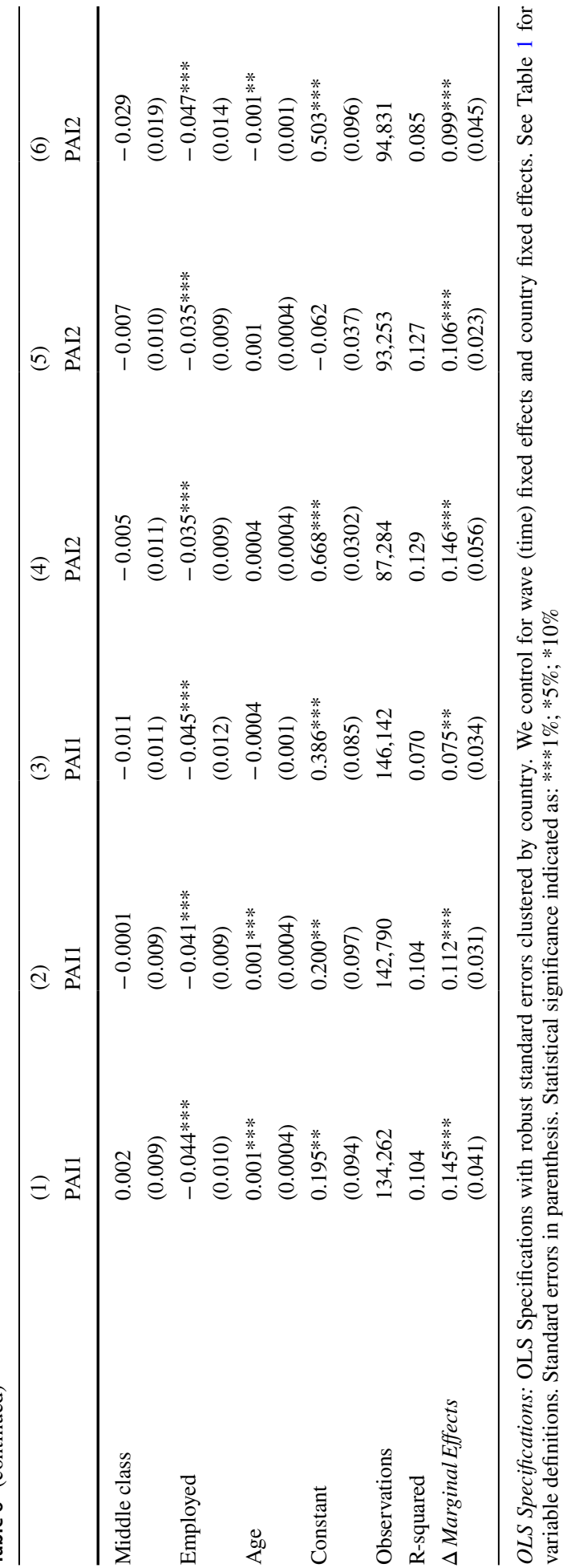


Under such circumstances, Borin and Mancini (2016) advocate the use of inverse probability weight (IPW) estimates. ${ }^{9}$ In this context, IPW estimates can reduce sample selection bias by creating a carefully matched control group (Mallick \& Yang, 2013; Webster $\&$ Piesse, 2018). While it is impossible to observe the same individual under two circumstances as a perfect control, using IPW we can create a counterfactual based on individuals with all matching characteristics with the exception of their values for individualism and/or collectivism. In essence, IPW estimates correct for the fact that each individual is observed only in one of the potential outcomes by using estimated probability weights to find similar individuals in the sample on all other dimensions.

For IPW estimation, the dependent variables need to be binary. At the same time, the treatment and control groups need to be defined in two mutually exclusive groupings (high individualism, low collectivism) and (low individualism, high collectivism). Thus, for the dependent variables, we consider all four individual survey question measures that we have used in different combinations to make the various PAI indices. They are 'Men Better Political Leaders', 'Univ. for Boys', 'Men Better Bus. Execs.', and 'Men Right to Job'. We consider our benchmark measures of individualism and collectivism to create the binary treatment groups based on whether the values are above or below the average values. For columns (1), (3), (5) and (7), we consider above average individualism and below average collectivism along with trust. For columns (2), (4), (6) and (8), we consider below average individualism and above average collectivism in conjunction with trust. We remind our readers that all indices are standardized in terms of mean and standard deviation and, thus, means are around zero. We present the average treatment effects (ATE) from our IPW estimations in Table 7.

For treatment groups with above average individualism and below average collectivism, we find the ATEs to be negative and significant as expected, and similarly, the opposite when individualism is below average and collectivism is above average. The effects again are in the range of values estimated earlier, in fact slightly larger on average, and are easily visible here as simply the difference in the two values which were would be 14.6, 6.5, 11.0, and 15.5 percentage points. Thus, if anything this technique strengthens the magnitude of our results and conclusions.

\section{Conclusion}

High levels of social trust are not always associated with positive attitudes toward gender equality. In fact, often high levels of trust have developed in societies through a process that further entrenched traditional patriarchal attitudes and beliefs, rather than eroding them. Because social trust evolves over time based on commercial and exchange relationships, we hypothesize that this differential is caused by whether these exchanges occurred in societies founded on individual beliefs in individualism or collectivism.

\footnotetext{
9 As has been pointed in the literature, finding instruments for multiple variables that meet the externality restrictions and are orthogonal to the error term can be extremely challenging. Murray (2006) and Baum (2008) point out that the finite-sample properties of IV estimates are problematic especially in the presence of weak instruments. If instruments are weak, IV estimators may not be an improvement over OLS estimators (Clemens et al., 2012). Persson and Tabellini (2006) note the difficulty in finding efficient, time varying instruments that are strictly exogenous. Thus, we restrict our identification strategies towards mitigating omitted variable bias and simultaneity bias.
} 


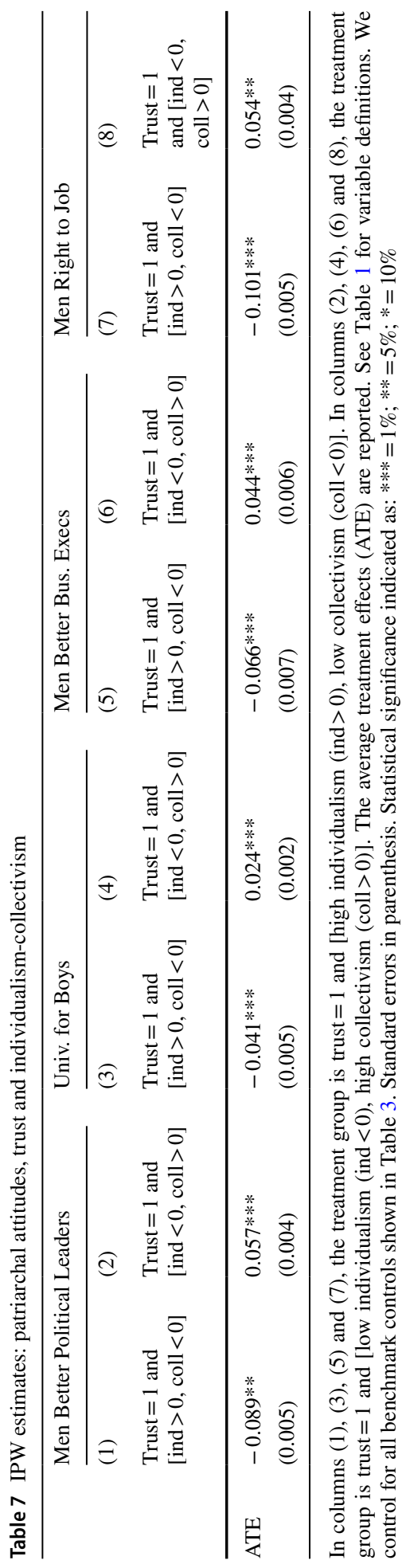


In individualistic societies, with low levels of collectivism, exchange relationships historically evolved to be more inclusive of women in the trading and production processes. As women played a greater role in economic exchange, the trust that these exchanges fostered also worked to improve attitudes regarding women's equality in business, civil, and political interactions broadly.

In contrast, in collectivistic societies with low individualism, patriarchal roles were further entrenched through exchanges that were not only based on social obligations rather than mutual gain, but also often conducted by the patriarchal male leaders of family or economic units on behalf of the group. In this exchange process women's desires and goals were subservient to the needs of the group or unit in the context of its contribution to overall societal goals and obligations.

We test and confirm our hypothesis using a large panel of data from the World Values Survey (WVS), and our results are robust to a large number of different measurements and estimation methods. What we find is that even in groups of individuals for which high levels of social trust have evolved, they continue to hold patriarchal values if they belong to social groups embracing collectivistic beliefs and refuting individualism. At the other end of the spectrum, in social groups embracing individualism and refuting collectivism, high levels of social trust are associated with diminished patriarchal views in favor of gender equality.

Perhaps the most important implication of our analysis stems from the fact that these social values will continue to evolve in the future, and thus modern collectivistic beliefs stand as a barrier to the future development of societies in which women's economic rights, achievements, and goals are better valued and recognized; and in which social trust is extended beyond traditional gendered roles. Approximately half of the countries in the world still place one or more restrictions on women's economic activities and ownership. If these societies that can make significant shifts away from values of collectivism and toward individualism they will move to empower women in economic exchange and help to reduce these gendered and discriminatory barriers over the years to come.

Acknowledgements We thank the editor and the referees for their invaluable comments and suggestions. N. Dutta and R.S. Sobel would like to dedicate this paper to the memory of their beloved co-author Sanjukta Roy whose life was taken way too early by COVID-19.

\section{References}

Arrow, K. (1972). Gifts and Exchanges. Philosophy and Public Affairs, 1(4), 343-362.

Baliamoune-Lutz, M. (2007). Globalization and gender inequality: Is Africa different? Journal of African Economies, 16(2), 301-348.

Baum, C. (2008). Using instrumental variables techniques in economics and finance. German Stata Users' Group Meetings, Stata Users Group.

Bergh, A., \& Bjørnskov, C. (2011). Historical trust levels predict the current size of the welfare state. Kyklos, 64(1), 1-19.

Berry, D. W., Golder, M., \& Milton, D. (2012). Improving tests of theories positing interaction. The Journal of Politics, 74(3), 1-19.

Beugelsdijk, S., de Groot, H. L. F., \& van Schaik, A. B. T. M. (2004). Trust and economic growth: A robustness analysis. Oxford Economic Papers, 56, 118-134.

Beugelsdijk, S., Maseland, R., \& van Hoorn, A. (2015). Are scores on Hofstede's dimensions of national culture stable over time? A cohort analysis. Global Strategy Journal, 5, 223-240.

Binder, C. C. (2019). Redistribution and the individualism-collectivism dimension of culture. Social Indicators Research, 142, 1175-1192. 
Bjørnskov, C. (2009). Social trust and the growth of schooling. Economics of Education Review, 28, $249-257$.

Bjørnskov, C. (2012). How does social trust lead to economic growth? Southern Economic Journal, 78, 346-1368.

Bjørnskov, C., \& Méon, P.-G. (2015). The productivity of trust. World Development, 70(C), 317-331.

Borin, A., \& Mancini, M. (2016). Foreign direct investment and firm performance: an empirical analysis of Italian firms. Review of World Economics, 152(4), 705-732.

Brambor, T., Clark, W., \& Golder, M. (2006). Understanding interaction models: Improving empirical analyses. Political Analysis, 14(1), 63-82.

Braumoeller, B. (2004). Hypothesis testing and multiplicative interaction terms. International Organization, 58(4), 807-820.

Cho, J.-H., Chan, K., \& Adali, S. (2015). A survey on trust modeling. ACM Computing Surveys, 28, 1-40.

Clark, M., Ouellette, R., Powell, M., \& Milberg, S. (1987). Recipient' s mood, relationship type, and helping. Journal of Personality and Social Psychology, 53, 94-103.

Clemens, M., Radelet, S., Bhavnani, R., \& Bazzi, S. (2012). Counting chickens when they hatch: Timing and the effects of aid on growth. Economic Journal, 122(561), 590-617.

Cline, B. N., \& Williamson, C. R. (2017). Individualism, democracy, and contract enforcement. Journal of Corporate Finance, 46, 284-306.

Coleman, J. (1988). Social capital in the creation of human capital. American Journal of Sociology, 94, S95-S120.

Coleman, J. S. (1990). The Foundations of Social Theory. Cambridge, Mass: Harvard University Press.

Crenshaw, K. W. (2017). On Intersectionality: Essential Writings. The New Press.

Dasgupta, P. (2005). Economics of social capital. Economic Record, 81, S2-S21.

Davis, L., \& Abdurazokzoda, F. (2016). Language, culture and institutions: Evidence from a new linguistic dataset. Journal of Comparative Economics, 44(3), 541-561.

Davis, L. S., \& Williamson, C. R. (2016). Culture and regulation of entry. Journal of Comparative Economics, 44(4), 1055-1083.

Davis, L. S., \& Williamson, C. R. (2019). Does individualism promote gender equality? World Development. https://doi.org/10.1016/j.worlddev.2019.104627

de Soto, H. (1989). The other path: The invisible revolution in the third world. Harper \& Row.

de Soto, H. (2000). The mystery of capital: Why capitalism triumphs in the west and fails everywhere else. Basic Books.

Dearmon, J., \& Grier, R. (2011). Trust and the accumulation of physical and human capital. European Journal of Political Economy, 27(3), 507-519.

Del Boca, D. \& Locatelli, M. (2006). The determinants of motherhood and work status: A survey. IZA discussion paper, 2414.

Delhey, J., \& Newton, K. (2005). Predicting cross-national levels of social trust: Global pattern or Nordic exceptionalism? European Sociological Review, 21(4), 311-327.

Dinda, S. (2008). Social capital in the creation of human capital and economic growth: A productive consumption approach. The Journal of Socio-Economics, 37, 2020-2033.

Donno, D., \& Russett, B. (2004). Islam, authoritarianism, and female empowerment: What are the linkages? World Politics, 56(4), 582-607.

Durante, R. (2009). Risk, cooperation and the economic origins of social trust: An empirical investigation. http://ssrn.com/abstract=1576774

Fernandez, R., Fogli, A., \& Olivetti, C. (2004). Mothers and sons: Preference formation and female labor force dynamics. Quarterly Journal of Economics, 119(4), 1249-1299.

Forsythe, N., \& Korzeniewicz, R. P. (2000). Gender inequalities and economic growth: A longitudinal evaluation. Economic Development and Cultural Change, 48(3), 573-617.

Fukuyama, F. (1996). Trust: The social virtues and the creation of prosperity. Free Press Paperbacks.

Gambetta, D. (2000). Can we trust trust? In D. Gambetta (Ed.), Trust: Making and breaking cooperative relations, chapter 13, electronic edition (pp. 213-237). University of Oxford.

Gorodnichenko, Y., \& Roland, G. (2011). Which dimensions of culture matter for long-run growth? American Economic Review, 101(3), 492-498.

Gorodnichenko, Y., \& Roland, G. (2017). Culture, institutions and the wealth of nations. The Review of Economics and Statistics, 99(3), 402-416.

Greif, A. (1994). On the political foundations of the late medieval commercial revolution. Genoa during the twelfth and thirteenth centuries. Journal of Economic History, 54, 271-287.

Guiso, L., Sapienza, P., \& Zingales, L. (2008). Social capital as good culture. Journal of the European Economic Association, 6, 295-320. 
Guiso, L., Sapienza, P., \& Zingales, L. (2009). Cultural biases in economic exchange. Quarterly Journal of Economics, 124, 1095-1131.

Hamamura, T., Li, L. M. W., \& Chan, D. (2017). The association between generalized trust and physical and psychological health across societies. Social Indicators Research, 134, 277-286.

Hayek, F. A. (1988). The fatal conceit: The errors of socialism. The University of Chicago Press.

Heineck, G. (2004). Religion, attitudes towards working mothers, and wives' full time employment: Evidence for Austria, Germany, Italy, the UK, and the US. Austrian Institute for Family Studies, 39.

Hofstede, G. (1980). Culture's consequences: International differences in work-related values. Sage.

Hofstede, G. (2001). Culture's consequences: Comparing values, behaviors, institutions, and organizations across nations (2nd ed.). Sage.

Hosseini, S. A. H., \& Lawrence, J. S. (2018). How 'critically open-minded' are we? An Australian perspective through the world values survey. Social Indicators Research, 136, 1211-1236.

Hudler, M., \& Richter, R. (2002). Cross-national comparison of the quality of life in Europe: Inventory of surveys and methods. Social Indicators Research, 58, 217-228.

Johnson, N. D., \& Mislin, A. (2012). How much should we trust the World Values Survey trust question? Economics Letters, 116(2), 210-212.

Knack, S., \& Keefer, P. (1997). Does social capital have an economic payoff? A cross-country investigation. Quarterly Journal of Economics, 112(4), 1251-1288.

LaPorta, R., Lopez-de-Silanes, F., Shleifer, A., \& Vishny, R. (1997). Trust in large organizations. The American Economic Review, 87, 333-338.

Li, L. M. W., \& Bond, M. H. (2010). Does individual secularism promote life satisfaction? The moderating role of societal development. Social Indicators Research, 99, 443-453.

Licht, A. N., Goldschmidt, C., \& Schwartz, S. H. (2007). Culture rules: The foundations of the rule of law and other norms of governance. Journal of Comparative Economics, 35, 659-688.

Luhmann, N. (2000). Familiarity, confidence, trust: Problems and alternatives. In D. Gambetta (Ed.), Trust: making and breaking cooperative relations, chapter 6, electronic edition (pp. 94-107). University of Oxford.

Mallick, S., \& Yang, Y. (2013). Productivity performance of export market entry and exit: Evidence from Indian firms. Review of International Economics, 21(4), 809-824.

Markus, H. R., \& Kitayama, S. (1991). Culture and the self: Implications for cognition, emotion, and motivation. Psychological Review, 98, 224-253.

Mikucka, M., Sarracino, F., \& Dubrow, J. K. (2017). When does economic growth improve life satisfaction? Multilevel analysis of the roles of social trust and income inequality in 46 countries, 1981-2012. World Development, 93, 447-459.

Misztal, B. A. (1996). Trust in modern societies. Polity Press.

Murray, M. (2006). Avoiding invalid instruments and coping with weak instruments. Journal of Economic Perspectives, 20(4), 111-132.

Newton, K. (1997). Social capital and democracy. American Behavioral Scientist, 40(5), 575-586.

Nooteboom, B. (2007). Social Capital, institutions, and trust. Review of Social Economy, 65(1), $29-53$.

Ostrom, E. (1998). A behavioral approach to the rational choice theory of collective action: Presidential address. The American Political Science Review, 92(1), 1-22.

Özcan, B., \& Bjornskov, C. (2011). Social trust and human development. The Journal of Socio-Economics, 40(6), 753-762.

Papagapitos, A., \& Riley, R. (2009). Social trust and human capital formation. Economics Letters, 102, $158-160$.

Persson, T., \& Tabellini, G. (2006). Democracy and development: The devil in the details. American Economic Review, 99(2), 319-324.

Probst, T. M., Carnevale, P. J., \& Triandis, H. C. (1999). Cultural values in intergroup and single-group social dilemmas. Organizational Behavior and Human Decision Processes, 77(3), 171-191.

Putnam, R. (2000). Bowling alone: The collapse and revival of American community. Simon and Schuster.

Seguino, S. (2007a). Plus ca change? Evidence on global trends in gender norms and stereotypes. Feminist Economics, 13(2), 1-28.

Seguino, S. (2007b). The great equalizer? Globalization effects on gender equity in well-being in Latin America and the Caribbean. In A. Shaikh (Ed.), Globalization and the myth of free trade (pp. 177214). Routledge.

Seguino, S. (2011). Help or hindrance? Religion's impact on gender inequality in attitudes and outcomes. World Development, 39(8), 1308-1321.

Singelis, T. M., Triandis, H. C., Bhawuk, D. P. S., \& Gelfand, M. J. (1995). Horizontal and vertical dimensions of individualism and collectivism: A theoretical and measurement refinement. Cross-Cultural Research, 29, 240-275. 
Steele, L. G., \& Lynch, S. M. (2013). The pursuit of happiness in China: Individualism, collectivism, and subjective well-being during China's economic and social transformation. Social Indicators Research, $114,441-451$.

Stone, M. (2018). A place of her own: Women's right to land. Council on Foreign Relations. Women and Foreign Policy Program and Women Around the World.

Tabellini, G. (2008). Presidential address: Institutions and culture. The Journal of the European Economic Association, 6(2-3), 255-294.

Tabellini, G. (2010). Culture and institutions: Economic development in the regions of Europe. Journal of the European Economic Association, 8(4), 677-716.

Tesch-Romer, C., Motel-Klingebiel, A., \& Tomasik, M. J. (2008). Gender differences in subjective wellbeing: Comparing societies with respect to gender equality. Social Indicators Research, 85, 329-349.

Tonkiss, F., Passey, A., Fenton, N., \& Hems, L. (2000). Trust and civil society. Palgrave Macmillan.

Torpe, L., \& Lolle, H. (2011). Identifying social trust in cross-country analysis: Do we really measure the same? Social Indicators Research, 103, 481-500.

Triandis, H. C. (2001). Individualism-collectivism and personality. Journal of Personality, 69, 907-924.

Triandis, H. C., \& Gelfland, M. J. (1998). Converging measurement of horizontal and vertical individualism and collectivism. Journal of Personality and Social Psychology, 74, 118-128.

Uslaner, M. E. (1999). Democracy and social capital. In M. E. Warren (Ed.), Democracy and trust (pp. 121-150). Cambridge University Press.

Uslaner, M. E. (2003). Trust, democracy and governance: Can government policies influence generalized trust? In M. Hooghe \& D. Stolle (Eds.), Generating social capital: Civil society and institutions in comparative perspective. Palgrave Macmillan.

Webster, A., \& Piesse, J. (2018). Are foreign-owned firms more likely to pay bribes than domestic ones? Evidence from emerging markets. World Development, 12, 12. https://doi.org/10.1016/j.worlddev. 2017.08.007

Whiteley, P. (2000). Economic growth and social capital. Political Studies, 48, 443-466.

Yadav, U. N., Rayamajhee, B., Mistry, S. K., Parsekar, S. S., \& Mishra, S. K. (2020). A syndemic perspective on the management of non-communicable diseases amid the COVID-19 pandemic in low- and middle-income countries. Frontiers in Public Health, 8, 1-7.

Zak, P. J., \& Knack, S. (2001). Trust and growth. The Economic Journal, 111, 295-321.

Zhang, Y., Kao, G., \& Hannum, E. (2007). Do mothers in rural China practice gender equality in educational aspirations for their children? Comparative Education Review, 51(2), 131-157.

Publisher's Note Springer Nature remains neutral with regard to jurisdictional claims in published maps and institutional affiliations. 